\title{
Pitching people with an inversion table: Estimates of body orientation are tipped as much as those of visual surfaces
}

\author{
Dennis M. Shaffer ${ }^{1}$ Ally Taylor ${ }^{1} \cdot$ Allyson Thomas $^{1} \cdot$ Phil Graves $^{1} \cdot$ Echoe Smith $^{1}$. \\ Eric McManama ${ }^{1}$
}

Published online: 10 November 2015

(C) The Psychonomic Society, Inc. 2015

\begin{abstract}
In the current work we investigate people's perception of their own body tilt in the pitch direction. In Experiment 1, we tilted people backward at 1 of 5 different randomly assigned angles using an inversion table. People significantly overestimated the angle at which they were tilted backward at angles from $8^{\circ}$ to $45^{\circ}$. The slope of the plotted average overestimates had a gain of 1.46 , fitting nicely with previously reported gains of verbal overestimates of visually perceived slant of natural outdoor geographically oriented slopes as well as man-made wooden slopes within and outside of reach in the laboratory. In Experiment 2, we showed participants a $45^{\circ}$ line and asked them to indicate when they were positioned at that orientation. Participants again significantly overestimated the angle at which they were tilted backward. This extends work showing that a scale-expanded theory of visual space is multisensory, results in equivalent estimates for both verbal and nonverbal/nonnumeric methods, and can now be expanded to include the perceived orientation of one's own body.
\end{abstract}

Keywords Slant perception $\cdot$ Spatial orientation $\cdot$ Pitch

For the last two decades, a wealth of evidence shows that people overestimate the slant of both geographical and manmade slopes by between $5^{\circ}$ and $25^{\circ}$ (Bhalla \& Proffitt, 1999; Bridgeman \& Hoover, 2008; Creem \& Proffitt, 1998; CreemRegehr, Gooch, Sahm, \& Thompson, 2004; Durgin \& Li, 2011; Durgin, Li, \& Hajnal, 2010; Hajnal, Abdul-Malak, \&

Dennis M. Shaffer

shaffer.247@osu.edu

1 Department of Psychology, The Ohio State University, Mansfield, 1760 University Drive, Mansfield, OH 44906, USA
Durgin, 2011; Li \& Durgin, 2010; Proffitt, Bhalla, Gossweiler, \& Midgett, 1995; Proffitt, Creem \& Zosh, 2001; Shaffer \& Flint, 2011; Shaffer \& McManama, 2015; Stefanucci, Proffitt, Clore, \& Parekh, 2008; Witt \& Proffitt, 2007). Much less work has been performed on people's perception of their own body orientation in the pitch dimension, and the results of some of this work are difficult to interpret. For instance, Cohen and Larson (1974) had participants adjust the pitch of their own body every $15^{\circ}$ from a supine position to a prone position while restrained in a motorized hospital bed. They found systematic errors of underestimation of body tilt. For instance, when asked to place themselves at $15^{\circ}$ backward from a vertical position, they placed themselves at $29^{\circ}$ backward, and when asked to place themselves at $15^{\circ}$ forward, they placed themselves at $23^{\circ}$ forward. These errors were consistent but smaller as they moved in either direction in $15^{\circ}$ increments from $15^{\circ}$ to $60^{\circ}$, at which point there was almost no error. Of the studies to investigate pitch perception, this seems to be the only one where people underestimate pitch. We feel there are at least two reasons for this. First, participants were moved backward in $15^{\circ}$ increments until they were prone, and then forward in $15^{\circ}$ increments until they were in a supine position. They did this back and forth a total of eight times (four backward, four forward). Carryover effects from each previous estimate likely affected their subsequent estimate. Second, they were giving estimates of, say, $15^{\circ}$ backward when they were either erect (straight up and down) or oriented at $30^{\circ}$ backward (depending on whether they were in the forward or backward sequence). Separate analyses were not reported for forward and backward sequences, so it is not known whether there were anchoring biases that could strongly affect their estimates and whether these were symmetrical or not (Shaffer, McManama, Swank, Williams, \& Durgin, 2014; Shaffer, McManama, \& Durgin, in press). 
More recently, Ito and Gresty (1997) assessed postural orientation in the pitch dimension while participants were in seated and standing positions. Participants were instructed to estimate when they felt like they were tilted $45^{\circ}$ forward and backward and $90^{\circ}$ forward and backward. When their head, trunk, and legs were in alignment ("Protocol 5") and they estimated they were at $45^{\circ}$ backward, they were actually positioned at $32^{\circ}$ backward (from erect), and when they estimated they were at $45^{\circ}$ forward they were actually positioned at $37^{\circ}$ forward. This provides evidence that people overestimate how much they are tilted in the pitch dimension. However, participants either tilted themselves or were tilted by the experimenter $45^{\circ}$ forward prior to estimating when they were tilted backward at $45^{\circ}$, so it is difficult to say whether or by how much participants were affected by this, especially in the seated condition where their estimates of $45^{\circ}$ backward averaged $4^{\circ}$ backward and their estimates of $90^{\circ}$ backward averaged $47^{\circ}$ backward.

Jewell (1998) was able to control for some of the factors making it difficult to interpret the aforementioned work by asking participants to estimate only one angle. He performed a series of experiments tilting people backward in chairs, "hand trucks," or a gyroscope with eyes open and eyes closed. Participants were tilted from vertical (Study 1, Experiments 1 \& 2 and Study 2, Experiment 1) and asked to indicate when they were tilted backward at a $45^{\circ}$ angle. When participants were tilted backward while seated in chairs or while standing in hand trucks estimates were significantly earlier than $45^{\circ}$. When participants stood in the gyroscope and were tilted backward, they estimated they were tilted at $45^{\circ}$ when they were only tilted at $32.94^{\circ}$ (eyes open), similar to Ito and Gresty (1997), and $28.74^{\circ}$ (eyes closed).

The current work had four purposes. First, we wanted to extend previous work, by performing a systematic investigation of people's perception of their own body tilt in the pitch dimension. Therefore, we tilted people backward at five different randomly assigned angles $\left(8^{\circ}, 16^{\circ}, 24^{\circ}, 32^{\circ}\right.$, and $\left.40^{\circ}\right)$ and recorded their estimates of the angles at which they perceived they were tilted. We did this to test whether there is a pattern of overestimation across a wide range of angles. Second, we wanted to tilt people backward from straight up and down until they perceived they were tilted backward at $45^{\circ}$ and compare these results with those of Jewell (1998). Third, we wanted to have people match their body to a nonverbal diagram of a $45^{\circ}$ line in order to test whether a nonverbal and nonnumeric method would yield equivalent results to verbal estimations. Finally, we sought to investigate whether the pattern of results we would find for proximal slant or the perceived orientation of one's own body at the five different angles is similar to the pattern seen for the verbal estimates of distal slanted surfaces. Li and Durgin (2010) developed a model that predicted that surfaces would be overestimated by a factor of 1.5. They found that virtual surfaces with viewing distances of between 1 and $16 \mathrm{~m}$ were overestimated by a factor of 1.5 , with longer viewing distances resulting in larger slant bias, and this model provided an excellent fit to the verbal overestimates of eight natural outdoor hills reported by Proffitt et al. (1995). Durgin and Li (2011), Experiment 3, also found that eight slopes ranging from $4.2^{\circ}$ to $48^{\circ}$, and at distance at either $1 \mathrm{~m}$ or $2.5 \mathrm{~m}$ were overestimated by a factor of 1.49 . This same "gain" of 1.5 has also been found for downhill slopes of $16^{\circ}$, $24^{\circ}$, and $32^{\circ}$ (Li \& Durgin, 2009, Experiment 3 ) and for surfaces within reach ranging from $12^{\circ}$ to $42^{\circ}$ (Durgin et al., 2010). It is important to extend the results of these previous findings of scale expansion across different modes of representing spatial orientation (haptic, vestibular, and visual).

\section{Experiment 1}

\section{Method}

\section{Participants}

A total of 60 undergraduates ( 42 female) from The Ohio State University, Mansfield, participated in the experiment in fulfillment of an introductory psychology requirement. Their mean age was $19.93(S D=3.89)$ years.

\section{Materials and apparatus}

A Teeter Hang-Ups NXT-S ${ }^{\circledR}$ Inversion Table was used to tilt participants backward to desired angles of $8^{\circ}, 16^{\circ}, 24^{\circ}, 32^{\circ}$, and $40^{\circ}$. The table's adjustable ankle system locked to comfortably hold participants' ankles in place. One of several weightlifting belts, depending on the size of the participant, was placed around the participants' waist and the back of the inversion table, securing the upper body of the participant. This is shown in Fig. 1. An Accuremote ${ }^{\mathrm{TM}}$ precision angle measurement gauge was placed on the spine-like frame of the inversion table to measure the angle at which participants were tilted when they gave their estimates. The readings of the inclinometer were within $\pm 0.25^{\circ}$ of the desired angle $\left(8^{\circ}, 16^{\circ}, 24^{\circ}, 32^{\circ}\right.$, or $\left.40^{\circ}\right)$. Participants were instructed to keep their hands down at their sides and to keep their head flat against the inversion table the entire time.

\section{Procedure}

Participants were randomly assigned to either the eyes-open or eyes-closed condition. Participants stepped into the ankle supports and secured the belts around their waists as an experimenter adjusted the ankle supports. Prior to giving any estimates, all participants were given a brief review of standard geometry to clarify that they understood different angular positions. We explained that when the inversion table was standing vertically, it was defined to be at $0^{\circ}$ and when the table was lying horizontally, it was at $90^{\circ}$. We did not proceed until all participants clearly understood the instructions. We pseudo randomized the order in 


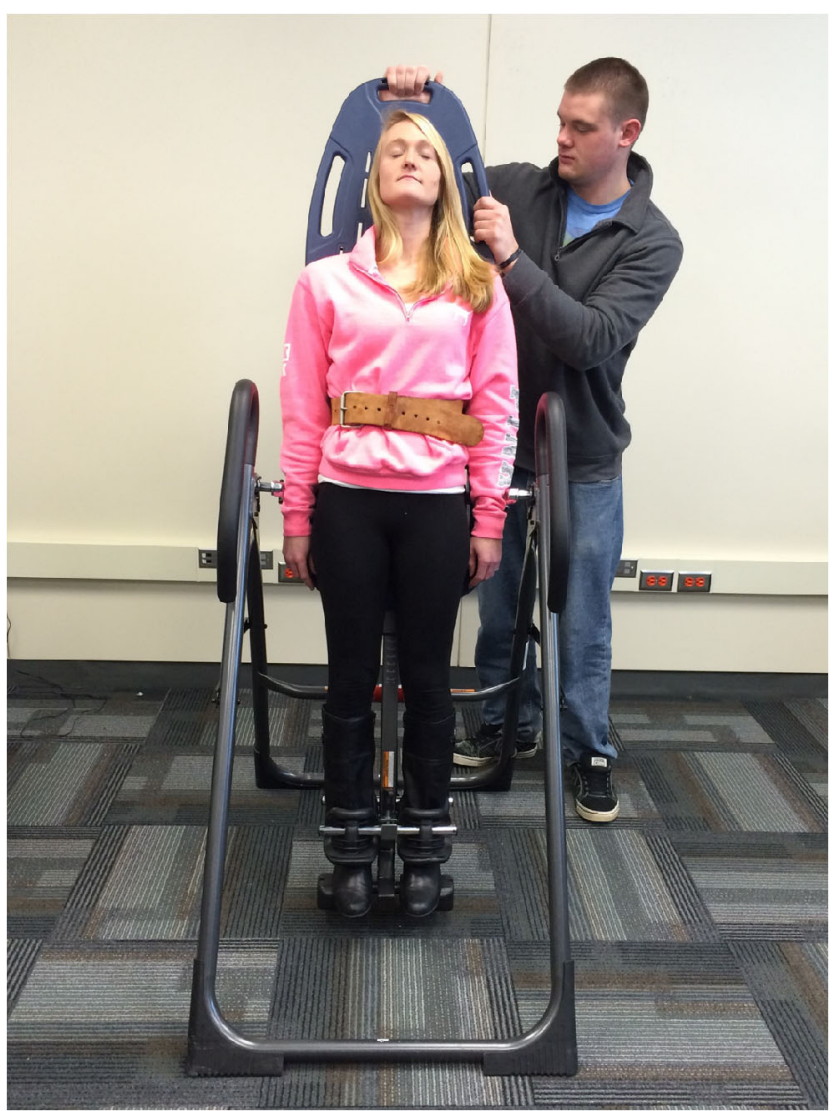

Fig. 1 Here the participant is shown being tilted back in the inversion table by an experimenter in the eyes-closed condition

which the angles were presented and used this same order for all of the participants. The order of the angles was: $32^{\circ}, 24^{\circ}, 8^{\circ}, 16^{\circ}$, and $40^{\circ}$. We did this to avoid a situation in which one participant would get slowly ascending or descending trials, and to avoid $8^{\circ}$ and $40^{\circ}$ orientations to be used back to back. We felt that given the exaggerations we expected, tilting them back to $8^{\circ}$ then $40^{\circ}$ or $40^{\circ}$ and then $8^{\circ}$, might unnecessarily exacerbate the alreadyexpected exaggerated estimations.

For each trial, participants were tilted backward manually with a rotational velocity of approximately 4 to 6 degrees per second. Once participants were tilted at one of the five angles, they gave a verbal estimate of at what angle they thought they were tilted backward from $0^{\circ}$. They were returned to $0^{\circ}$ (straight up and down) after giving their verbal response for each angle. ${ }^{1}$

\footnotetext{
${ }^{1}$ While we returned the participants to $0^{\circ}$ or vertical (erect) prior to making each of their estimates, we are confident that these results were not affected by anchoring as when Jewell (1998) manipulated starting position at either $0^{\circ}$ or $90^{\circ}$, perceived tilt in the backward-forward direction was not affected by starting position. In addition, had we minimized anchoring by moving participants from one angle to the next, we would have confounded backward and forward movement and provoked participants to rely on the previous angle for their estimate of the subsequent angle, both of which we wanted to avoid. Additionally, we sought to test what the perceived $45^{\circ}$ backward estimates were, not what perceived $45^{\circ}$ forward estimates were.
}

The instruction when we tilted them back at $45^{\circ}$ was different. Here, participants were told they would be tilted backward slowly by the male experimenter who stood behind the inversion table and were then told to verbally stop him when they felt they had reached $45^{\circ}$. This measure was counterbalanced, with half of the participants estimating when they were tilted at $45^{\circ}$ prior to their estimates of the other five angles and the other half of participants estimating when they were tilted at $45^{\circ}$ after their estimates of the other five angles.

We did not tilt them forward for several reasons. First, our inversion table did not allow us to do that. Second, Jewell (1998) already found that there was no difference between tilting people backward and tilting people forward in terms of their exaggerated estimates. This is supported by published work using an Aerotrim where forward and backward conditions differed by only $\sim 1^{\circ}$ (Naylor \& McBeath, 2008).

\section{Results}

We first performed independent-samples $t$ tests to compare the estimates of the five different angles between the eyes open and eyes closed conditions. We used a Bonferroni correction of $p=.05 / 5=.01$ for each analysis for the multiple $t$ tests. We found no statistical difference for any of the angles between eyes open and eyes closed conditions, $8^{\circ}: t(58)=-.25, p=$ $.803 ; 16^{\circ}: t(58)=-.9, p=.372 ; 24^{\circ}: t(58)=.97, p=.332 ; 32^{\circ}:$ $t(58)=-1.68, p=.098 ; 40^{\circ}: t(58)=-1.55, p=.126$. Given that there were no significant differences between eyes open and eyes closed conditions, we collapsed across conditions for the remaining analyses. Table 1 shows these means and standard deviations for each of the five angles.

We next performed 5 one-sample $t$ tests comparing people's estimates to the actual angles. We again used a Bonferroni correction of $p=.05 / 5=.01$ for each analysis for the multiple $t$ tests. We found that people significantly overestimated how much they were tilted backward at each angle, $8^{\circ}: t(59)=3.51, p=.001$, Cohen's $d=.543 ; 16^{\circ}: t(59)=$ $5.95, p<.001$, Cohen's $d=.77 ; 24^{\circ}: t(59)=3.97, p<.001$, Cohen's $d=0.51 ; 32^{\circ}: t(59)=6.49, p<.001$, Cohen's $d=.84$; $40^{\circ}: t(59)=10.39, p<.001$, Cohen's $d=1.34$.

In order to test the pattern of people's estimates across the different angles at which they were tilted backward, we plotted the estimates for each of the five different angles for each participant. We then calculated and recorded the slope for each participant. We then performed a one-sample $t$ test comparing the slopes (or "gains") of our 60 participants to 1.5 , the gain

Table 1 Mean body orientation estimates and standard deviations

\begin{tabular}{llllll}
\hline Angle & $8^{\circ}$ & $16^{\circ}$ & $24^{\circ}$ & $32^{\circ}$ & $40^{\circ}$ \\
Mean & $10.55^{\circ}$ & $22.27^{\circ}$ & $30.02^{\circ}$ & $44.53^{\circ}$ & $58.18^{\circ}$ \\
$S D$ & $5.63^{\circ}$ & $9.45^{\circ}$ & $11.73^{\circ}$ & $14.96^{\circ}$ & $13.56^{\circ}$ \\
\hline
\end{tabular}


that has been found for near and far surfaces and for both geographical slopes outdoors as well as man-made slopes studied in laboratories. We found that there was no significant difference between the gains of our participants and a gain of $1.5, t(59)=-.74, p=.461,, M=1.457,95 \%$ CI $[1.34,1.57]$. Average estimates of body orientation at each angle are shown in Fig. 2, and they fit a straight line very well, $R^{2}=.9881$.

Finally, we tested whether people's estimates of when they were tilted backward at $45^{\circ}$ were significantly different from $45^{\circ}$, and then compared them to earlier reports. Here, we expect numbers that are less than $45^{\circ}$ if they are overestimating how much they think they are tilted backward. This is functionally equivalent to our participants giving estimates that are greater than the angle at which they were actually tilted. An independent-samples $t$ test revealed no significant difference between eyes open and eyes closed conditions, $t(58)=0.73, p$ $=.47$, and so we collapsed the conditions. A one-sample $t$ test showed that estimates of $45^{\circ}$ were significantly less than $45^{\circ}$, indicating a significant overestimation of slant, $t(59)=-14.45$, $p<.001$, Cohen's $d=1.87, M=28.35^{\circ}, S D=8.93^{\circ}$. An independent-samples $t$ test found no effect of order in which asking them to stop when they felt they were tilted backward at $45^{\circ}$ (before or after asking them to verbally estimate the other five angles), $t(58)=0.66, p=.948, M_{B}=61.71, M_{A}=$ 61.58 .

\section{Discussion}

We have found systematic errors in people's perceived pitch orientation of their own bodies. In general, people thought they were tilted significantly farther backward at every angle from $8^{\circ}$ to $45^{\circ}$, irrespective of whether their eyes were open or closed. These overestimates seem slightly more pronounced at angles of greater than $24^{\circ}$. This is similar to the results of $\mathrm{Li}$ and Durgin (2010), who modeled the slant data of Proffitt et al. (1995). Our results are consistent with previous work showing that people overestimate how much they are tilted backward when asked to estimate when they are tilted backward at $45^{\circ}$ (Ito \& Gresty, 1997; Jewell, 1998). These results were functionally equivalent to those of Jewell (1998). ${ }^{2}$ If people were overestimating where they were tilted by a factor of 1.5 in the $45^{\circ}$ condition, then one would expect them to say they were at $45^{\circ}$ when they were only at $\sim 30^{\circ}$. We compared the mean estimate to $30^{\circ}$ using a one-sample $t$ test and found that the overestimates in this condition were by a factor no

\footnotetext{
$\overline{2}$ It was not clear whether the eyes-open condition was statistically different from the eyes-closed condition in Jewell (1998), as there were 12 conditions and all participants were in all 12 conditions. So we performed 2 one-sample $t$ tests comparing the means from Jewell's eyes-open $(M=$ $\left.32.94^{\circ}\right)$ and eyes-closed $\left(M=28.74^{\circ}\right)$ conditions (Study 2, Experiment 1) using a Bonferroni correction of $p=.025$. The one-sample $t$ tests found no significant differences between eyes-open and eyes-closed conditions across experiments, $t(29)=2.15, p=.040$, and $t(29)=0.82, p=.422$.
}

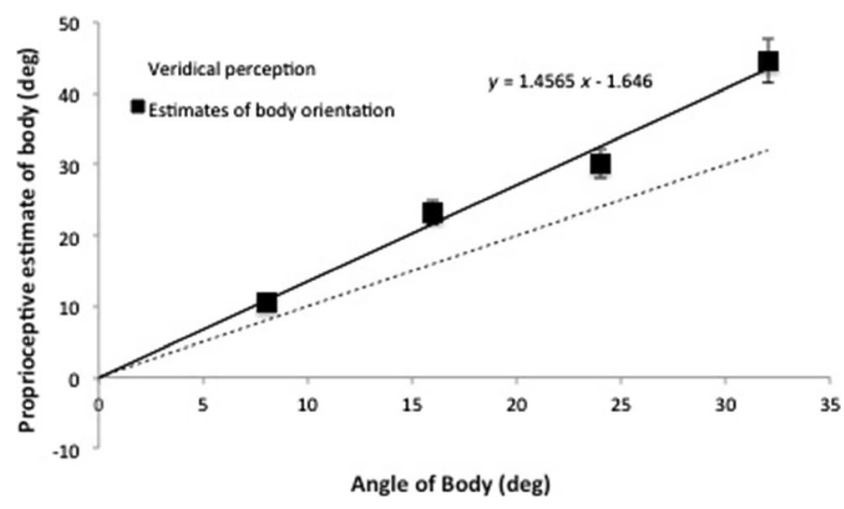

Fig. 2 Mean estimates of body orientation at each angle, with error bars representing $\pm 1 S E M$. The trend line (solid line) shown is the best fitting linear function. The dotted line indicates how the line would look if people estimated the angles perfectly

different than $1.5, t(59)=-1.44, p=.156$. These results are also consistent with those of Li and Durgin (2009, Experiment 2B) who had people produce five different head-pitch orientations, one of which was $45^{\circ}$, while wearing a head-mounted display. They too produced a mean forward head pitch comparable to the $28.35^{\circ}$ found when our participants were asked to tell us when they were tilted backward at $45^{\circ}$.

\section{Experiment 2}

Experiment 1 had people verbally estimate the pitch of their own body. It is possible that people perceive body pitch accurately but are not as good at verbally estimating angles. So in Experiment 2 we sought to test people's estimate of their own pitch orientation using a diagram. We showed participants a nonverbal diagram showing a $45^{\circ}$ line and asserted that it was halfway between vertical and horizontal. We then asked participants to produce this orientation instead of tilting them at $45^{\circ}$ and asking them to verbally estimate at what angle they are tilted. The advantage of this method is that it avoids the concern that participants don't understand degrees. If people overestimate how much they are tilted backward, then we would expect them to tell us to stop earlier than $45^{\circ}$ to indicate the halfway point between vertical and horizontal, much like the participants from our Experiment 1 did.

\section{Method}

\section{Participants}

A total of 60 undergraduates ( 35 female) from The Ohio State University, Mansfield, participated in the experiment in fulfillment of an introductory psychology requirement. Their mean age was $19.03(S D=3.57)$ years. None had participated in Experiment 1. 


\section{Materials and apparatus}

The same Teeter Hang-Ups NXT-S ${ }^{\circledR}$ Inversion Table used in Experiment 1 was used to tilt participants backward. The table's adjustable ankle system locked to comfortably hold participants' ankles in place. One of several weightlifting belts, depending on the size of the participant, was placed around the participants' waist and the back of the inversion table, securing the upper body of the participant. This is shown in Fig. 1. An Accuremote precision angle measurement gauge was placed on the spine-like frame of the inversion table to measure the angle at which participants were tilted when they gave their estimates. Participants were instructed to keep their hands down at their sides and to keep their head flat against the inversion table the entire time.

\section{Procedure}

Participants were randomly assigned to either the eyes-open or eyes-closed condition. Participants were randomly assigned to either the eyes open or eyes closed condition. Participants stepped into the ankle supports and secured the belts around their waists as an experimenter adjusted the ankle supports. We showed participants a line oriented at $45^{\circ}$ told them that it was "halfway" between vertical and horizontal. We then asked participants to produce this orientation, instead of verbally asking for " $45^{\circ}$ " as we did in Experiment 1. Here, participants were told they would be tilted backward slowly by the male experimenter who stood behind the inversion table and were then told to verbally stop him when they felt they had reached the position of the oriented line they were shown. For each trial, participants were tilted backward with a rotational velocity of approximately 4 to 6 degrees per second.

\section{Results}

We first performed an independent-samples $t$ test to compare the estimates of the $45^{\circ}$ angle between the eyes-open and eyes-closed conditions. We found no statistical difference between eyes-open and eyes-closed conditions, $t(58)=-0.72, p$ $=.475, M_{\text {EyesOpen }}=27.3^{\circ}, S D=8.09^{\circ}, M_{\text {EyesClosed }}=29^{\circ}, S D$ $=10.21^{\circ}$. Given that there were no significant differences between eyes-open and eyes-closed conditions, we collapsed across conditions for the remaining analyses. We next performed a one-sample $t$ test comparing people's estimates to the actual orientation of the line shown in the diagram $\left(45^{\circ}\right)$. Here, we expect numbers that are less than $45^{\circ}$ if they are overestimating how much they think they are tilted backward. We found that people's estimates of halfway between vertical and horizontal as shown in the diagram (an angle of $45^{\circ}$ ) were significantly less than $45^{\circ}$, indicating a significant overestimation of slant, $t(59)=-14.23, p<.001$, Cohen's $d=$ $1.84, M=28.15^{\circ}, S D=9.17^{\circ}$, Cohen's $d=1.84$. These results are virtually identical to, and no different statistically from those of Experiment 1, where the mean verbal estimate was $28.35^{\circ}, t(118)=-0.12, p=.907, M_{\operatorname{Exp} 1}=28.15^{\circ}$.

\section{Discussion}

Experiment 2 showed that people overestimate their own body pitch orientation using a nonverbal/nonnumeric method. These results were equivalent to those of our Experiment 1, when we asked people to verbally estimate when they were tilted backward at $45^{\circ}$. Here, we expect numbers that are less than $45^{\circ}$ if they are overestimating how much they think they are tilted backward. This is functionally equivalent to our participants giving estimates that are greater than the angle at which they were actually tilted, and this occurred irrespective of whether they were asked to do this verbally or by using a nonverbal/nonnumeric method.

This joins a growing body of recent work showing that nonverbal methods match verbal estimates regarding slant. For instance, recently, measures of matching extent and remote haptic perception have been supportive of a single underlying representation that is exaggerated to the same extent as the results are for verbal and visual matching estimates $(\mathrm{Li}$ \& Durgin, 2010; Shaffer \& McManama, 2015). Li and Durgin (2010) had one group of people compare the relative length of a frontal extent to that of an extent that was placed up a virtual hill (tilted back in depth). This provides, by trigonometry, an implicit estimate of perceived slant. The other group gave verbal estimates of the same hill. The implicit slant measure gave the same results of the verbal estimates - both showed the same exaggeration of all slants. Shaffer and McManama (2015) used a remote haptic device in which the participant holds one end of a wooden dowel ( 1-1.5 $\mathrm{m}$ in length) while exploring an $\sim 1 \mathrm{~m}$ inclined surface. The remote haptic task allows exploration of the surface itself, using proprioceptive feedback, and is also an action-based measure very good at affording appropriate action upon the same slanted surface on which it is used (Fitzpatrick, Carello, Schmidt, \& Corey, 1994; Malek \& Wagman, 2008; Regia-Corte \& Wagman, 2008). The slope of the gain of estimates across six inclinations using the remote haptic task was exactly the same slope of 1.5 (ratio of estimate:actual inclination) that has been shown for verbal estimates of virtual and geographical hills, nonverbal matching estimates, and haptic estimates using a finger to explore slanted surfaces (Durgin \& Li, 2012; Hajnal et al., 2011). Additionally, overestimation has been found in other nonverbal tasks including visual matching (Bhalla \& Proffitt, 1999; Proffitt et al., 1995), pedal perception (Hajnal et al. 2011), haptic perception (Durgin, et al., 2010), and downward gaze (Li \& Durgin, 2009).

Our data also nicely fit the pattern of results found with verbal estimates of the visually perceived slant of natural outdoor hills as well as wooden hills typically used indoors in 
laboratories (Li \& Durgin, 2010). We have shown that the gain of proximal slant, or the perceived orientation of one's own body at the five different angles, is similar to the gains seen for the verbal estimates of visually perceived distal slanted surfaces. The model of Li and Durgin (2010) is based on their work showing that people's perceived declination of gaze has a gain of about 1.5. So in order to see the ground plane as horizontal, we expand the scale of the ground by a factor of 1.5 to perceive it as being horizontal. In the eyes-open condition, perceived declination of gaze could also help to explain why people's estimates nicely fit a scale expansion model with a gain of 1.5. However, it seems more likely that some combination of perceived body orientation along with vision results in overestimation of body tilt by a factor of 1.5. In the eyes-closed condition, the expanded scale of slant is not coded by visual experience alone and so must be multisensory. Evidence to support these ideas comes from pedal perception of slopes from blind observers who overestimate how much slopes are tilted as much as sighted individuals, and from blindfolded individuals who overestimate the slope of a ramp when stood upon more than verbally estimating the same sloped ramp when looking at it (Hajnal et al., 2011). That same work also showed that verbal estimates of surfaces explored by the finger reliably overestimated the actual slopes of those surfaces. Consistent with this, the aforementioned remote haptic perception work from our laboratory has investigated people's exploring a ramp sloped at different angles using a $1 \mathrm{~m}$ wooden dowel rod that they hold in their hand, without looking at the ramp. They overestimate the angles by a factor of 1.5, the same factor of overestimation given by people looking at the ramp and giving verbal estimates (Shaffer \& McManama, 2015). Figure 3 shows verbal estimates of a visually perceived sloped ramp, verbal estimates after haptic exploration of the same ramp with a wooden dow$\mathrm{el}$, and the current estimates of the angles when being tilted in

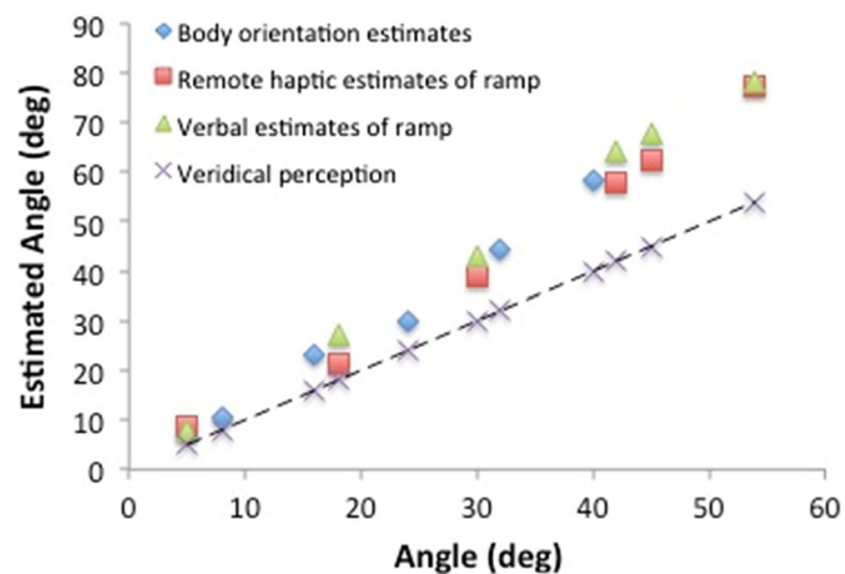

Fig. 3 Verbal estimates of a visually perceived sloped ramp, verbal estimates after haptic exploration of the same ramp with a wooden dowel, and the current estimates of the angles when being tilted in the inversion table the inversion table. The slopes of the lines that best fit these estimates are 1.4695 (verbal), 1.4498 (remote), and 1.4565 (body orientation).

From ours and previous work, it is difficult to know yet whether vision, touch, and/or body proprioception work as additive effects for estimating slant or more as complementary factors that serve to give us redundant information about the perceptual coding of space in different ways. What the current work does show us is that people significantly overestimate the perceived pitch of their own body at a variety of angles and that these overestimates seem to reflect a scale expansion theory of space, now further extended beyond that of just vision to whole body proprioception.

\section{References}

Bhalla, M., \& Proffitt, D. R. (1999). Visual-motor recalibration in geographical slant perception. Journal of Experimental Psychology: Human Perception and Performance, 25, 1076-1096.

Bridgeman, B., \& Hoover, M. (2008). Processing spatial layout by perception and sensorimotor interaction. The Quarterly Journal of Experimental Psychology, 61, 851-859.

Cohen, M. M., \& Larson, C. A. (1974). Human spatial orientation in the pitch dimension. Perception \& Psychophysics, 16, 508-512.

Creem, S. H., \& Proffitt, D. R. (1998). Two memories for geographical slant: Separation and interdependence of action and awareness. Psychonomic Bulletin and Review, 5, 22-36.

Creem-Regehr, S. H., Gooch, A. A., Sahm, C. S., \& Thompson, W. B. (2004). Perceiving virtual geographical slant: Action influences perception. Journal of Experimental Psychology: Human Perception and Performance, 30, 811-821. doi:10.1037/0096-1523.30.5.811

Durgin, F. H., \& Li, Z. (2011). Perceptual scale expansion: An efficient angular coding strategy for locomotor space. Attention, Perception, \& Psychophysics, 73, 856-1870. doi:10.3758/s13414-011-0143-5

Durgin, F. H., \& Li, Z. (2012). Spatial biases and the haptic experience of surface orientation. In A. El Saddik (Ed.), Haptics rendering and applications (pp. 75-94). Rijeka, Croatia: InTech.

Durgin, F. H., Li, Z., \& Hajnal, A. (2010). Slant perception in near space is categorically biased: Evidence for a vertical tendency. Attention, Perception, \& Psychophysics, 72, 1875-1889. doi:10.3758/APP.72. 7.1875

Fitzpatrick, P., Carello, C., Schmidt, R. C., \& Corey, D. (1994). Haptic and visual perception of an affordance from upright posture. Ecological Psychology, 6, 265-287.

Hajnal, A., Abdul-Malak, D. T., \& Durgin, F. H. (2011). The perceptual experience of slope by foot and by finger. Journal of Experimental Psychology: Human Perception and Performance, 37, 709-719. doi: $10.1037 / \mathrm{a} 0019950$

Ito, Y., \& Gresty, M. A. (1997). Subjective postural orientation and visual vertical during slow pitch tilt for the seated human subject. Aviation, Space, \& Environmental Medicine, 68, 3-12.

Jewell, J. G. (1998). The misperception of body tilt: Support for an ecologically-guided multisensory representation of space. Unpublished doctoral dissertation, Kent State University.

Li, Z. \& Durgin, F. H. (2009). Downhill slopes look shallower from the edge. Journal of Vision, 9(11), 6, 1-15. doi:10.1167/9.11.6

Li, Z., \& Durgin, F. H. (2010). Perceived slant of binocularly viewed large-scale surfaces: A common model from explicit and implicit 
measures. Journal of Vision, 10(14), 13, 1-16. doi:10.1007/s00221011-2934-2

Malek, E. A., \& Wagman, J. B. (2008). Kinetic potential influences visual and remote haptic perception of affordances for standing on an inclined surface. The Quarterly Journal of Experimental Psychology, 61, 1813-1826.

Naylor, Y. K., \& McBeath, M. K. (1998). Gender differences in spatial perception of body tilt. Perception \& Psychophysics, 70, 199-207. doi:10.3758/PP.70.2.199

Proffitt, D. R., Bhalla, M., Gossweiler, R., \& Midgett, J. (1995). Perceiving eographical slant. Psychonomic Bulletin and Review, 2, 409-428.

Proffitt, D. R., Creem, S. H., \& Zosh, W. D. (2001). Seeing mountains in mole hills: Geographical-slant perception. Psychological Science, 12, 418-423.

Regia-Corte, T., \& Wagman, J. B. (2008). Perception of affordances for standing on an inclined surface depends on height of center of mass. Experimental Brain Research, 191, 25-35.

Shaffer, D. M., \& Flint, M. (2011). Escalating slant: Increasing physiological potential does not reduce slant overestimates. Psychological Science, 22, 209-211. doi:10.1177/0956797610393744
Shaffer, D. M., McManama, E., Swank, C., Williams, M., \& Durgin, F. H. (2014). Anchoring in action: Manual estimates of slant are powerfully biased toward initial hand orientation and are correlated with verbal report. Journal of Experimental Psychology: Human Perception and Performance. doi:10.1037/a0036217

Shaffer, D. M., McManama, E., \& Durgin, F. H. (in press). Manual anchoring biases in slant estimation affect matches even for near surfaces. Psychonomic Bulletin \& Review.

Shaffer, D. M., \& McManama. E. (2015). Remote haptic perception of slanted surfaces shows the same scale expansion as visual perception. Attention, Perception, \& Psychophysics. Advance online publication. doi:10.3758/s13414-014-0814-0

Stefanucci, J. K., Proffitt, D. R., Clore, G. L., \& Parekh, N. (2008). Skating down a steeper slope: Fear influences the perception of geographical slant. Perception, 37, 321-323. doi:10.1068/p5796

Witt, J. K., \& Proffitt, D. R. (2007). Perceived slant: A dissociation between perception and action. Perception, 36, 249-257. doi:10. $1068 / \mathrm{p} 5449$ 